\title{
Analysis of Students'Argumentation Skill and Conceptual Knowledge in Friction Force Lesson through Argumentative Task
}

\author{
Rendi Restiana Sukardi \\ Science Education, Post Graduate School \\ Universitas Pendidikan Indonesia \\ Bandung, Indonesia \\ rendisukardi@ymail.com
}

\author{
Yanti Vrida Agustrianti \\ Science Teacher \\ SD Istiqamah \\ Bandung, Indonesia \\ yantivrida@gmail.com
}

\begin{abstract}
Scientific phenomenon found in daily life is highly related to friction force. However, students are not capable in comprehending that phenomenon conceptually or contextually. In the end, the science class is felt as less meaningful. Generally, students' answers in learning process is very limited and is not able to show their true thinking skill. This affects the concept knowledge which students already have. The thinking process can be indicated by the argument given by students in experiment. Based on the evaluation in the experiment, students haven't been able to comprehend the abstract concept friction force. Thus, a media is needed to initiate student in order to develop students' argumentation skills and their conceptual knowledge. The methodology used in this study is descriptive study. Twenty one students from one of Islamic elementary school were chosen as the participants of this study. The finding shows that the arguments given by students are $100 \%$ at the first level (in the task of use the complex data), $76 \%$ at the first level and $24 \%$ at the second level (at the task of conflicting hypothesis), and $86 \%$ at the first level and $14 \%$ at the second level (in the task of post-investigating discussion). At the final learning session, the average score for comprehending basic knowledge conceptually is $\mathbf{9 1 . 8 1}$, whereas the argumentation skill of students is at the first level $(\mathbf{7 8 . 0 9 \%})$ and the second level $(21.91 \%)$. The correlation coefficient between the conceptual knowledge and argumentation skill $(r=0.19)$ is very low or extremely low. Therefore, in the next learning session, the argumentative task should be combined with science literature to give students' insight in giving argument. In the end of learning session, teacher gave a question to students. The result shows that argumentative task rises up students' motivation and curiosity to learn science topic, where $\mathbf{7 1 . 4 2 \%}$ students said yes and $\mathbf{2 8 . 5 8 \%}$ students said no.
\end{abstract}

Keywords-Argumentation Skill; Conceptual Knowledge; Friction Force; Argumentative Task

\section{INTRODUCTION}

Although any scientific argumentation has important role in learning, there are some sentiments which claim that argument as not futile stuff. Morerover, implementing the argument-based learning method is not easy because there are challenges from teacher, curriculum goals, and evaluation [6]. Considering that fact, it can be seen that there is a gap between science education and learning fact because the argumentation process is disregarded [8]. This situation doesn't give any good impact for the science education development because students' high potential is disregarded as well. The thing that teacher can do is to choose the learning method which can develop students' argumentation skill, including their conceptual knowledge. One of the learning methods is the argumentative task which was developed by Kind et al[6].

The expected conceptual knowledge from argumentativebased science learning is not only students' skill in remembering facts, but it is expected to gain high quality conceptual knowledge. The finding from the previous study shows that the development of argumentation skill affects conceptual knowledge. This finding is supported by another finding from different research which shows a relatable connection between argumentation skill and conceptual knowledge [2]. Furthermore, there is a possibility of linear pattern between argumentation skill toward student's conceptual knowledge.

In this study, researchers was interested to implement science learning method using argumentation based in friction topic with argumentative task, which was adapted from Kind et al [6]. The underlying reason behind the theme chosen was because the scientific phenomenon around friction found in daily life. However, student is incapable in comprehending that phenomenon conceptually or contextually. Thus, the learning activity in the class and the phenomenon in real life seem not having any relation. Furthermore, based on teaching experience, students' reasoning in solving the contextual problem is very limited and unable to show students' thinking process. The thinking process in understanding scientific phenomenon is detected by the argument given by students. Based on those facts, teaching friction force using argumentative task is needed to enhance students' argumentation skill and conceptual knowledge, and to create a qualified learning activity which results in students with high argumentation skill.

In relevance to the background above, the research question of this study is what are the impacts of the implementing argumentative task in learning friction force toward students' argumentation skill and conceptual knowledge. The research questions are elaborated below: 
1. How are the argumentation processes in learning friction force?

2. How are students' conceptual knowledge in learning friction force?

3. How are students' argumentation skills in learning friction force?

4. How is the relation between students' conceptual knowledge and argumentation skill in learning friction force?

Conceptual Knowledge is one of the dimensions of Taxonomy Bloom cognitive thinking process. This knowledge is related to the symbol, concept, and its relation. The form can be principals which are revealed with or without theorem. This can be presented in proportion and formula, picture, or diagram [10]. In Taxonomy Bloom range revision, the conceptual knowledge which is measured are the process of remembering $(\mathrm{C} 1)$, understanding $(\mathrm{C} 2)$, and implementing (C3).

Argumentation skill is related to the argument quality. In other words, it is identified by the objection part in the argument. This skill can be seen through written test. The argument quality was categorized based on the argument parts, which are level 1, level 2, level 3, and level 4 . The evaluation form was adapted from Erduran et al [7].

The implementation was started by giving some argumentative tasks in several meetings with different characteristics [6], which are:

\section{- $\quad$ Use of complex data}

In order to supporting the argumentation process, this task showed some data to students without leading students to create a correct conclusion. The purpose of this kind of argumentative task is similar with consensus condition to reach a justified agreement and propose consensus solution to the problem [7].

Conflicting Hypothesis

In this case, students faced two different hypothesis theory. Students doubted the correct statement of doing a research in term of learning material. But students have to convince their choice or hypothesis by means of a good justification. It is like in the persuasive condition [7].

Post-Investigation Discussion

This strategy was aimed to aks students to do a reflection based on various scientific research which were already done. The task is a revision based on the previous task. Students were asked to give any comments toward the investigation.

\section{RESEARCH METHOD}

The methodology used in this study is a descriptive study. This descriptive method is the appropriate one to draw a phenomenon and situation originally [9].

\section{A. Research Design}

In this study, there was no model or learning method applied along with particular sintax or typical characteristic. Instead, the argumentative task as the media was used to help student in creating an argument. The steps were done through the experiment, learning with argumentative task, and evaluation as the reflection to improve the next learning session.

\section{B. Participants and Research Site}

This study was conducted at one of elementary school in Bandung. This school has science laboratory which is representable and equipped. Further, the students can access information through various sources which is helpful in their learning activity where argumentative task is applied in the class and laboratory. The population in this study were students from $V_{A}, V_{B}$, and $V_{C}$ classes which have relatively similar. Meanwhile, the sample for this study was chosen between one of those classes. The sampling technique was a random sampling, a technique of randomly taking sample which opens the same possibility for every population to be sample [4].

\section{Data Collection and Data Analysis}

The data collection of this study was done through several steps: assessing written test to find students' argumentation skill and conceptual knowledge, analyzing students' argumentative task. The written test was conducted after the learning activity was finished. Meanwhile, the argumentative task was given during the learning activity.

Students' conceptual knowledge was obtain through written test with 10 numbers of short essay. Those problems were already validated by science teachers. After the test was done, students' scores were gathered, along with the average score among them.

The argumentation activity and argumentation skill were obtained through analyzing the constituent of their arguments. The constituents are claim, data, warrant, backing, qualifier, and rebuttal [3]. Students' argumentation skills were categorized into level 1,2,3, and 4. The argument level 1 only contains simple claim, the level 2 consists of claim and supporting evidence/data, level 3 consists of claim, warrant, backing, data, or qualifier but there is no rebuttal. Meanwhile, the argument level 4 consists of claim, data, warrant, backing, or qualifier completed by rebuttal.

In order to processing the data, argumentation skill was changed into score, thus the correlation between conceptual knowledge and argumentation skill was easier to be analyzed. Level 1 of argument is scored 25, level 2 is 50, level 3 is 75 , and level 4 is 100 . Thus, there are numbers which represent student argumentation skill.

The next step was observing the relation between students' argumentation skill and conceptual knowledge. With using scatterplot, the general equation of a linear line is $y=m x+c$, where coefficient determination is $\mathrm{R} 2$. The value of coefficient determination is rooted to obtain the value of the correlation coefficient (r). The coefficient correlation is interpreted to see the relation between argumentation skill and conceptual knowledge. Here is the interpretation by Hasan [5]. 
TABLE I. CORRELATION INTERPRETATION

\begin{tabular}{|c|c|}
\hline $\begin{array}{c}\text { Correlation } \\
\text { Coefficient }\left(\mathbf{r}_{\mathrm{xy}}\right)\end{array}$ & Interpretation \\
\hline $\mathrm{r}_{\mathrm{xy}}=0.00$ & no correlation \\
\hline $0<\mathrm{r}_{\mathrm{xy}} \leq 0.20$ & very low correlation / very low \\
\hline $0.20<\mathrm{r}_{\mathrm{xy}} \leq 0.40$ & low correlation / weak but decent \\
\hline $0.40<\mathrm{r}_{\mathrm{xy}} \leq 0.70$ & meaningful correlation \\
\hline $0.70<\mathrm{r}_{\mathrm{xy}} \leq 0.90$ & high correlation/strong \\
\hline $0.90<\mathrm{r}_{\mathrm{xy}}<1.00$ & very high correlation / very strong, responsible \\
\hline $\mathrm{r}_{\mathrm{xy}}=1.00$ & perfect correlation \\
\hline
\end{tabular}

\section{RESULT AND DISCUSSION}

The friction learning session was done in two meetings. The learning activity in the first meeting was an experiment. There is finding obtained which is about the friction learning session used as the parameter in creating the learning activity for the next meeting.

Based on the presentation and discussion toward friction, generally, students were lacking in comprehending the material contextually. Students were able to understand friction conceptually, but they could not relate it to their daily activity. This is something normal because elementary school students are still unable to understand abstract things. Therefore, the argumentative task given to student should created a bridge between abstract problem to be real through the scientific phenomenon in daily life.

\section{A. Learning Profile}

In the first meeting, teacher facilitated students to do an experiment about friction force. The activity was intended to inject the basic concept of friction force. Teacher presented friction force phenomenon where students could observe how it works. The problem occurred when it was confirmed that students had a very low knowledge of how to implement the friction force to their daily life activity. Moreover, students are also incapable in telling their argument related with the result of their practice. This finding is the insight in arranging the argumentative task. This normally happened because their understanding of concepts only on real case. They haven't been able to imagine abstract or symbolic explanation.

The argumentative task has a role as starter, hence students' better argumentation. However, in the learning friction session, the argumentation could only obtain by written test. That was because the student found it difficult in understanding the whole concept of scientific phenomenon. Meanwhile, students were not familiar with building up opinion which were completed by data, warrant, backing, qualifier or even rebuttal. The lack of scientific literacy and factual thinking process are the some causes.

Table 2 presented the argumentation presentage which was appeared during the class discussion. The problem presented in complex data, starting student to give argumentation level 1 (100\%). Generally, students only give short answer related to question about the brakepads. This was caused by students don't know about kinds of brake pads. Almost all students tried to give reasoning and supporting evidence, however, the answer received was not correct because most of student only guessing.
The controvesion between the advantage and disadvantage of friction force in daily activity will be presented in different hypotesis. Students were asked to choose one of the appropriate hypotesis as the solution of discourse problem. This task succeeded to make student think of how to provide evidence and reason about the hypothesis that they support. Thus the result of student giving argument is level $1(76 \%)$ and level $2(23 \%)$.

TABLE II. NUMBER OF STUDENTS’ ARgUMENTATION

\begin{tabular}{|c|c|c|c|c|c|c|c|c|c|c|c|c|}
\hline $\begin{array}{c}\text { Kind of } \\
\text { Task }\end{array}$ & \multicolumn{4}{|c|}{$\begin{array}{c}\text { Use of Complex } \\
\text { Data }\end{array}$} & \multicolumn{4}{c|}{$\begin{array}{c}\text { Conflicting } \\
\text { Hypothesis }\end{array}$} & \multicolumn{3}{c|}{$\begin{array}{c}\text { Post- } \\
\text { Investigation } \\
\text { Discussion }\end{array}$} \\
\hline Level & 1 & 2 & 3 & 4 & 1 & 2 & 3 & 4 & 1 & 2 & 3 & 4 \\
\hline Number & 21 & 0 & 0 & 0 & 16 & 5 & 0 & 0 & 18 & 3 & 0 & 0 \\
\hline$\%$ & 100 & 0 & 0 & 0 & 76 & 24 & 0 & 0 & 86 & 14 & 0 & 0 \\
\hline
\end{tabular}

The next task was asking student to give a comment on the working steps in practice related to the friction concept. The argumentation occurred as level 1 (86\%) and level 2 (14\%).

If we look at the overall result, there is no rebuttal in any task. Students are not able to refuse or to give reason and strong evidence, hence there is no argumentation at level 3 or 4. That task presented various type of data and hypothesis, including the different steps in experiment.

Based on the interview result of teacher, we know that argumentative task is first time applied for them. Because of that, students couldn't develop their argument from the task. The more students engage in argumentation, the more they can generate claims, justify their claims with data and warrant, and support opposite position [2]. Students' argument while discussion could predict their quantity and quality of argumentation.

\section{B. Students' Conceptual Knowledge}

The concept or idea given by teacher related about friction are about the advantage and disadvantage. Some questions were chosen to avoid student making a guess in answering it. The measured conceptual knowledge is the process of how students memorize (C1), understand (C2), and implement (C3) the concept or idea about the the advantage and disadvantage of friction. We analized the conceptual knowledge questions from teacher. Most of questions included C1 (3 questions), C2 (4 questions), and C3 (questions). In the next learning session, we could arrange the composition to gain data accurately.

The average score obtained by students in answering the conceptual questions is 91.81. That score is considered as high. The composition of questions is probably one of the factor. In other hands, from the interview which was conducted with some students who got high score and some who got low score, it can be seen that students' motivation in learning is high. Therefore, those students own several text books about friction related. However, there is none of those books which can lead student to create an argument. Most of the books only present limited definition and explanation of friction force. Those kinds of book don't open opportunity to develop students' high quality of knowledge. 


\section{Students' Argumentation Skill}

Students' skill in giving argument about friction force was presented in a text or case. Students were asked to claim and complete it by data, warrant, qualifier, backing, even rebuttal. The result is presented in Figure 1. Based on the findings, it can be concluded that students' arguments are at level 1 (78.09\%) and level $2(21.91 \%)$.

We conducted interview with several students. From the interview we knew that students found several new terms of friction concept from argumentative task and teacher's explanations. These facts indicate that students' prior knowledge affects their participations in argumentations. If they were familiar with concepts or have scientific propositions about concept before starting argumentation, they will engage and generate argument component [2]. Most of students know what is friction force but only several of them who know kinds of break pads. Students were unable or unwilling to use scientific theories, models, or laws as a tool to make sense of a natural phenomenon and to evaluate scientific knowledge. This was because of they found new terms or concepts in science class. It could be barrier to greater student's achievement [8], included starting argumentations. Because of that, students have to read a lot of books to build their understanding of knowledge.

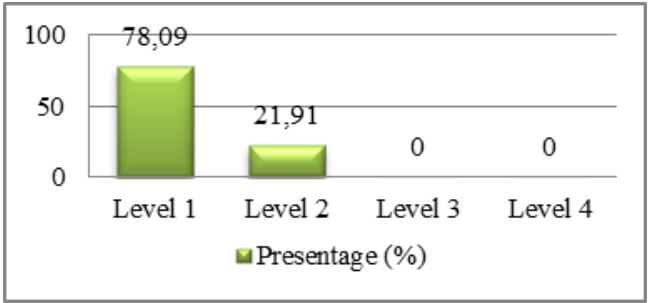

Fig. 1. Students' Argumentation Skill

\section{The Relation between Conceptual Knowledge and Argumentation Skill}

To find the relation between conceptual knowledge and argumentation skill, scatterplot was used on Microsoft Excel, hence the score of correlation coefficient $(r)$ was obtained. Coefficient correlation is interpreted to see how much one variable related to other variables. Axis $x$ is the variable of argumentation skill and axis $y$ is the variable of conceptual knowledge.

The coefficient correlation is $r=0.19$. The score of ' $r$ ' was obtained from root $\mathrm{R}^{2}$. This score indicates that the relation between students' argumentation skill and conceptual knowledge is low or very weak. This finding can be used as the suggestion and evaluation in implementing the future learning session to get better result. Below is presented the diagram of the result in Figure 2.

The good quality of conceptual knowledge is indicated by the presence of rebuttal [2]. Based on students' argumentation skill, we didn't find any rebuttals, but the average score of conceptual knowledge is relatively high.

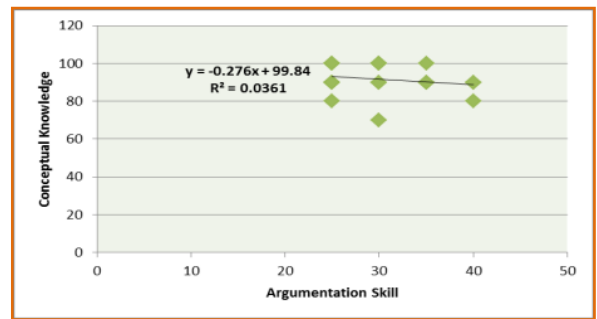

Fig. 2. The Relation of Students' Argumentation Skill and Conceptual Knowledge

The next step that could be done is making sure the reliability and validity of conceptual knowledge questions or we could use standard test which has good reliability and validity. So we could draw valid relationship between argumentation skill and conceptual knowledge.

\section{E. Reflection and Learning Evaluation}

Based on the analysis during the learning activity, there are several things which have to be taken into account in creating the plan for learning activity in the future. One of them is reading habit. Students have to accustom themselves to read scientific books more which can lead student to think and to create argument, so they don't memorize the information from the book only. It is suggested that argumentative task should not only collaborated with experiment, but it should be collaborated with science literacy as well. This is because of the importance of their prior knowledge. Thus, the number of student's participation in a discussion will be increased because students have much information. Moreover, to avoid the dominance of high-skilled student, teacher should arrange the limit of students' argument so the low- and middle- skilled students will not be unnoticeable.

Issues or ideas that are used as the argumentative task material should be validated the readability by student. The readability is about how tools or phenomenon is explained by students or not. Further, the material that used in the study should be a big idea which theme based. Thus, the range of students' thinking skill can be wider, and not only focused on specific stuff.

In the end of learning session, we gave a question to students about learning activity, whether it increases their curiosity to learn science topic. The result shows that $71.42 \%$ students said yes and $28.58 \%$ students said no. There were many reasons why they said yes. One of them because students were curious to give extended explanation. It rises up students' motivation to learn science topic.

\section{CONCLUSION}

Learning friction force with argumentative task has important role in helping students to think and to argue, although the result is not really optimal, which is only at the level 2. However, students' conceptual knowledge is good.

It is suggested to apply the argumentative task along with science literacy. Thus, students can obtain much relevant information with the topic that they learn. 


\section{References}

[1] Bekiroglu, F.O. and Eskin, H. (2012). Examination of The Relationship Between Engagement in Scientific Argumentation and Conceptual Knowledge. International Journal of Science and Mathematics Education. 10, (6), 1415-1443.

[2] Dawson, V. M., Venville, G. (2010). Teaching Strategies for Developing Students' Argumentation Skills About Socioscientific Issues in High School Genetics. Research Science Education. 40, (2), 133-148.

[3] Erduran, S., Simon, S., and Osborne, J. (2004). Tapping into Argumentation: Development in the Application of Toulmin's Argument Pattern for Studying Science Discourse. Science Education, 88(6), 915933.

[4] Fraenkel, J.R., Wallen, N.E., and Hyun, H.H. (2012). How to Design and Evaluate Research in Education. New York : McGraw-Hill.

[5] Hasan, M.I. (2002). Pokok-Pokok Materi Statistika 1 (Statistika Deskriptif). Jakarta : Bumi Aksara..

[6] Kind, P.M., Kind, V., Hofstein, A., Wilson, J. (2011). Peer Argumentation in the School Science Laboratory - Exploring Effects of Task Features. International Journal of Science Education. 33, (8), 2527-2558.

[7] Mila, M.G., Gilabert, S., Erduran, S., Felton, M. (2013). The Effect of Argumentative Task Goal on the Quality of Argumentative Discourse. Science Education. 97, (4), 497-523.

[8] Sampson, V., Grooms, J., Walker, J.P. (2011). Argument-Driven Inquiry as a Way to Help Students Learn How to Participate in Scientific Argumentation and Craft Written Arguments: An Exploratory Study. Science Education. 95, (2), 217-257.

[9] Sukmadinata, N.S. (2009). Metode Penelitian Pendidikan. Bandung : PT Remaja Rosdakarya.

[10] Ton de Jong, Hessler-Fergusson, MGM. (1996). "Types and Qualities of Knowledge”. Educational Psychologist. 31, (2), 105-113. 